Annuaire suisse de politique de développement

12 | 1993

Annuaire Suisse - Tiers Monde 1993

\title{
La Suisse et les pratiques commerciales restrictives
}

Die Schweiz und die wettbewerbsbeschränkenden Geschäftspraktiken

\section{Philippe Brusick}

\section{OpenEdition}

\section{Journals}

Édition électronique

URL : http://journals.openedition.org/aspd/1416

DOI : $10.4000 /$ aspd. 1416

ISSN : 1663-9669

\section{Éditeur}

Institut de hautes études internationales et du développement

\section{Édition imprimée}

Date de publication : 1 février 1993

Pagination : 193-206

ISSN : 1660-5934

\section{Référence électronique}

Philippe Brusick, «La Suisse et les pratiques commerciales restrictives », Annuaire suisse de politique de développement [En ligne], 12 | 1993, mis en ligne le 30 avril 2013, consulté le 08 septembre 2020. URL : http://journals.openedition.org/aspd/1416 ; DOI : https://doi.org/10.4000/aspd.1416 


\title{
La Suisse ef les pratiques commerciales restrictives*
}

\author{
Philippe Brusick *
}

La position de la Suisse dans le domaine de la concurrence peut paraître paradoxale à plus d'un titre. Petit pays extrêmement intégré dans le commerce mondial - plus de $60 \%$ de son PNB est tributaire des échanges avec l'étranger la Suisse est aussi le pays du protectionnisme le plus élevé dans le domaine agricole, dont les prix sont majorés de plus de $75 \%$ en moyenne, contre $38 \%$ pour la politique agricole commune de la Communauté européenne, pourtant si vivement critiquée! Pays du libéralisme économique - la liberté de commerce et d'industrie est garantie par la Constitution - la Suisse est aussi le siège de multinationales très puissantes, dont les pratiques commerciales restrictives sont tombées sous le coup des lois antitrust dans plusieurs pays étrangers. Félicitée par les experts du GATT pour sa politique commerciale libérale, elle n'en est pas moins critiquée par les mêmes experts du GATT pour les multiples ententes cartellaires qui caractérisent son marché intérieur et pour le manque de transparence des marchés publics au niveau des cantons et des communes, notamment. Ces mêmes critiques sur la politique de la concurrence de la Suisse sont reprises en force par l'OCDE dans son dernier rapport sur l'économie de la Suisse, qui va jusqu'à rendre les entraves à la concurrence sur le marché intérieur de la Suisse

* Vgl. Zusammenfassung S. 261.

** L'auteur est responsable du Groupe des Pratiques commerciales restrictives à la CNUCED, Genève. Toutefois, les opinions contenues dans cet article sont celles de l'auteur, et ne reflètent pas forcément celles de la CNUCED ou des Nations Unies. 
en partie responsables de l'excessive chèreté du pays $(40 \%$ de plus que la moyenne des prix de l'OCDE pour ce qui est de la consommation privée, et $30 \%$ de plus pour les dépenses d'équipement).

La nouvelle Loi fédérale sur les cartels et organisations analogues du 20 décembre 1985 a déjà eu des incidences favorables sur le démantèlement de nombreuses entraves à la concurrence, dans des domaines aussi variés que les banques, les assurances, la bière ou le ciment. II n'en reste pas moins que les pressions conjuguées de la déréglementation dans les pays développés, la globalisation des marchés mondiaux et les négociations commerciales multilatérales de l'Uruguay Round du GATT, ainsi que les changements fondamentaux en cours dans les pays à économie planifiée en transition vers l'économie de marché, et les réformes structurelles adoptées dans la plupart des pays en développement, ne peuvent qu'inciter la Suisse à s'ouvrir encore plus à la concurrence. L'accord sur l'Espace économique européen (EEE), s'il avait été accepté par la Suisse, aurait entraîné l'adoption pure et simple de l' "acquis communautaire" en matière de droit de la concurrence. Mais il ne faudra vraisemblablement pas attendre pour cela une adhésion de la Suisse à la Communauté. Les pressions sont telles que l'on parle déjà d'une nouvelle révision de la Loi fédérale sur les cartels.

\section{Les pratiques commerciales restrictives ou pratiques anticoncurrentielles}

En premier lieu, essayons de définir ce que l'on entend par pratiques commerciales restrictives (PCR). II s'agit d'accords ou d'ententes entre entreprises ayant pour objet de limiter ou de restreindre la concurrence. Peu importe que les entreprises en question soient publiques ou privées; ce qui compte, c'est qu'elles aient une activité commerciale, c'est à dire qu'elles soient engagées dans la production, la distribution ou la vente, dans un but lucratif.

Deux cas de figure peuvent se présenter. Dans le premier, on se trouve en présence de plusieurs offrants de produits identiques ou similaires qui sont naturellement concurrents sur un marché déterminé, que l'on appelle le "marché de référence". Plutôt que de se mesurer entre eux en faisant tout leur possible pour s'attirer les bonnes grâces de la clientèle - ce qui les contraindrait à abaisser leurs prix le plus possible, à améliorer leur service de vente et après vente, et même à investir lourdement dans la recherche et le développement pour innover et lancer de nouveaux produits répondant aux besoins et aux souhaits de leur clientèle - les offrants essaieront de s'entendre, justement pour éviter d'entrer en concurrence. Pour cela ils fixeront un prix de monopole, se répartiront les marchés et mettront leurs efforts en commun pour empêcher de nouveaux offrants de pénétrer sur "leur" marché. II s'agit là de ce que l'on appelle une "entente" ou "cartel". A noter que l'on peut classer les cartels selon le territoire qu'ils entendent couvrir; il existe donc des cartels nationaux, des cartels à l'importation, des cartels à l'exportation et des cartels internationaux. Dans ce dernier cas les membres du cartel proviennent de pays différents, et se partagent généralement des marchés tiers. 
Une pratique courante de tous les types de cartels ainsi décrits est la pratique des "soumissions collusoires", c'est-à-dire les soumissions truquées en réponse à un appel d'offres. Dans ce cas les membres du cartel se concertent secrètement lorsqu'ils sont en présence d'un appel d'offres, pour décider lequel d'entre eux sera désigné par le cartel pour faire l'offre la plus intéressante, et donc susceptible d'être choisie par le maître-d'oeuvre. Souvent le tour de chacun des membres est soigneusement précisé dans l'accord cartellaire. Par exemple, dans le cas du célèbre cartel des "phases de la lune" dans les années cinquante aux Etats-Unis, les fabricants de matériel électrique membres du cartel se partageaient les contrats suivant les phases de la lune.

L'entreprise à qui revenait le tour préparait une offre de monopoleur, sachant que les autres membres n'allaient pas la concurrencer. Pour sauver les apparences, les autres soumettaient des offres, mais bien-entendu, il s'agissait d'offres volontairement moins intéressantes, que le maître-d'oeuvre n'allait de ce fait pas retenir. Pour être sûrs de leur affaire, les membres dont ce n'était pas le tour, se basaient sur les calculs du gagnant présumé pour reconstruire leur propre offre, en majorant, par exemple tous les coûts d'un certain pourcentage. Et c'est ainsi que, dans de nombreux cas, l'existence de cartels a pu être prouvée, les fautes de calcul chez l'entreprise ayant fait la meilleure offre se retrouvant malencontreusement dans les soumissions des autres sociétés!

II faut encore préciser que tant que le cartel n'est pas découvert, les membres se partagent le "butin", c'est-à-dire la plus-value de monopole. Parfois même, le cartel prélève une part du butin pour mettre-de-côté des "réserves de guerre". Ces dernières seront utiles en cas d'entrée sur le marché d'un outsider,(non membre du cartel), qui essaierait de s'approprier une part du marché au détriment du cartel, dont les prix exagérément élevés sont faciles à concurrencer. Dans un tel cas, la "réserve de guerre" serait mise à contribution par le cartel, afin d'abaisser les offres jusqu'à vendre à perte si nécessaire, aussi longtemps qu'il faudra pour éliminer le gêneur soit en lui faisant faire faillite, soit en le convainquant de devenir membre du cartel.

Dans le deuxième cas de figure, on se trouve en présence d'une entreprise qui est soit en situation de monopole, c'est-à-dire en position de seul offrant sur le marché de référence, soit elle n'est pas seule, mais les autres offrants sont beaucoup plus petits, à tel point qu'ils sont incapables d'exercer une influence décisive sur les prix. La grande entreprise joue le rôle de leader en matière de prix, et les autres se bornent à adapter leurs offres à celles du leader. On dit d'une telle entreprise qu'elle est "en position dominante" sur le marché en question.

Les monopoles et les entreprises dominantes ont ceci de particulier qu'ils sont en mesure d'imposer des clauses restrictives sur leurs distributeurs (en aval) ou leurs fournisseurs (en amont). C'est pour cela que l'on appelle ce type de PCR des pratiques "verticales", par opposition aux cartels que l'on appelle des PCR "horizontales".

Une PCR verticale très courante est la pratique des "prix imposés". Par prix imposés on entend l'obligation pour le grossiste, et surtout pour le détaillant, de vendre les produits (de gros et surtout de détail) au prix fixé par le producteur. $\mathrm{Ce}$ 
dernier interdit toute vente au rabais de sa marchandise. En cas de refus d'obtempérer de la part du commerçant, le producteur peut menacer de refuser de le fournir à l'avenir. Cette pratique de "refus de vente", ou "boycottage", est une menace à prendre au sérieux lorsque l'on est en présence d'un fournisseur (producteur ou grossiste) en position dominante, car en cas de refus de vente, le détaillant aura de la peine à trouver un produit similaire ou identique, et son négoce se trouvera ainsi pénalisé.

Le refus de vente à la concurrence est implicite dans le contrat d'exclusivité. II s'agit bien là d'une PCR, mais dans de nombreux cas, il est admis que le producteur monte un réseau de distribution exclusif, surtout si le représentant doit investir des montants considérables pour être à la hauteur de représenter la marque en question, qu'il s'agisse de parfums ou d'automobiles. Au contrat d'exclusivité simple vient souvent s'ajouter l'"exclusivité réciproque", où le distributeur s'engage à son tour à ne pas vendre de produits concurrents.

Bien que souvent considérés comme des pratiques commerciales usuelles, les contrats d'exclusivité, ou les efforts tendant à convaincre les distributeurs de ne pas s'approvisionner chez les concurrents, lorsqu'ils proviennent de sociétés en "position dominante" sur le marché de référence, tombent sous le coup des lois de la concurrence dans certains pays. Ce fut le cas notamment, de la société pharmaceutique Hoffmann - La Roche, qui fut sévèrement sanctionnée en Allemagne, pour avoir appliqué un système de bonus de fin d'année en faveur des pharmacies qui ne s'approvisionnaient pas chez les concurrents. Hoffmann-La Roche fut considéré comme "entreprise dominante" par l'Office fédéral des cartels allemand.

La vente liée est une autre PCR qui peut avoir des effets néfastes sur les consommateurs, surtout si l'entreprise qui l'applique est en position dominante, car le consommateur ne pourra que difficilement s'adresser ailleurs. Il en va de même du détaillant voulant approvisionner son magasin d'un certain produit, et que le fabricant oblige à acheter toute une gamme de produits qu'il a de la peine à vendre, et qu'il ne désire pas tenir en rayon.

La discrimination injustifiée des prix et la fixation de prix "prédateurs" sont deux autres PCR dont les motivations sont souvent proches. Dans le premier cas, le fournisseur facture des prix différents à deux clients sans raison apparente telle que rabais de quantité ou prix de transport plus élevé à cause de la distance de livraison. Dans le deuxième, le prix est tellement bas, qu'il nuit à la concurrence, car les plus faibles ne peuvent pas suivre, et seule l'entreprise dominante restera présente sur le marché une fois les concurrents éliminés. On constate même des ventes à perte dans ce type de PCR, qui sont appelées "dumping" dans le commerce international.

Selon le GATT, il y a dumping lorsqu'un fabricant exporte moins cher qu'il ne vend dans son propre pays. Le caractère "prédateur" de cette pratique est reconnu, puisque les règles du GATT autorisent le pays importateur à lever des droits antidumping si l'industrie nationale de biens similaires ou identiques subit un préjudice grave. De la même manière, les subventions étatiques, qui faussent la concurrence sur les marchés internationaux, donnent lieu, au titre des règles du 
GATT, à des droits compensateurs. Quant à la Communauté européenne, son droit de la concurrence donne pleins pouvoirs à la Commission, qui est son organe exécutif, d' interdire les subventions lorsqu'elles faussent le jeu de la concurrence.

Une autre stratégie de prix anormalement bas est celle dite des "prix d'appel". Telle grande surface annoncera à grands frais de publicité une offre exceptionnelle sur tel ou tel produit jusqu'à épuisement du stock. Manque de chance, lorsque vous arrivez, le stock est épuisé. Afin de ne pas repartir les mains vides, vous vous rabattez sur un produit similaire, mais au prix fort! Les prix d'appel sont interdits par exemple en France.

La sous-facturation est un cas de figure qui fait partie de ce que l'on appelle aussi la pratique des "prix de transfert", et qui peut cacher une PCR visant à éliminer un concurrent. Le prix de transfert est le prix auquel une multinationale vend ses produits intermédiaires (les intrants) à une de ses filiales de production à l'étranger. Puisque maison mère et filiale font partie du même groupe, peut importe à la multinationale si le prix facturé à sa filiale correspond au prix (ou coût) réel de l'intrant en question. Cependant, si elle exagère ce prix, la filiale aura une structure des coûts plus élevée, et si la hausse n'est pas répercutée sur le prix de vente du produit fini, elle déclarera moins de profit, ou même une perte. Une pratique courante pour l'évasion fiscale ou la fuite des capitaux. Mais ce cas n'a pas d'incidence directe sur la concurrence, et n'est pas considéré à proprement parler comme une PCR. Par contre, la sous-facturation, c'est-à-dire lorsque le "prix de transfert" est inférieur à la réalité, permet à la filiale de vendre moins cher que ses concurrents et, en définitive, d'éliminer ces derniers, par application de prix prédateurs.

Un cas intéressant fut étudié en Argentine il y a quelques années par l'autorité chargée du respect de la concurrence dans ce pays. II s'agissait d'une multinationale étrangère qui fournissait des transistors à un fabricant de radios domestique. Tout alla pour le mieux jusqu'à ce que la multinationale décide d'installer sa propre filiale de production de radios en Argentine. A partir de ce moment, elle refusa de fournir le fabricant local aux mêmes conditions, et ce dernier se trouva en difficulté. C'est alors que la multinationale en question racheta les parts de la société, devenant ainsi un monopole.

Le phénomène de fusions et de rachats de sociétés est donc susceptible de créer des monopoles ou, tout au moins, des positions dominantes. C'est pourquoi, dans la plupart des pays ayant une loi sur la concurrence, l'état se donne également les moyens de contrôler la "concentration des marchés" et d'interdire, le cas échéant, les fusions-acquisitions jugées anticoncurrentielles.

\section{Le droit de la concurrence dans le monde et en Suisse}

C'est en Amérique du Nord, plus précisément au Canada que la première loi sur les cartels - la Combines Law - fut adoptée, à la fin du siècle dernier. Quelques années plus tard, en 1890,le fameux Sherman Antitrust Act fut adopté aux EtatsUnis. 
Le principe fondamental sur lequel s'appuie cette législation est celui de l'économie néo-classique selon lequel la concurrence assure une allocation optimale des ressources, pour le bien de l'économie en général, et des consommateurs en particulier.

II s'agissait d'éviter que les grands trusts de l'époque, de véritables conglomérats aux mains des grandes familles, ne monopolisent le pouvoir économique, et par là le pouvoir tout court. C'est pourquoi peu de temps après, le Congrès des Etats-Unis adopta une loi antitrust de plus, le Clayton Act, qui contient des dispositions permettant de contrôler les fusions et même, si nécessaire, de démanteler (to divest) les conglomérats.

Ce n'est qu'après la Seconde guerre mondiale que d'autres pays développés à économie de marché adoptèrent des lois similaires.

A noter toutefois que ces lois, adoptées en Angleterre, en France, dans les pays scandinaves, de même qu'en Allemagne et au Japon sous l'impulsion des EtatsUnis, étaient très loin d'être harmonisées; en fait, bien que partant des mêmes principes généraux se rapportant à la concurrence, elles étaient très différentes les unes des autres. Ce sont les lois allemandes et japonaises qui étaient les plus proches des lois américaines, puisque directement inspirées par le pays vainqueur et encore, les systèmes juridiques étant différents, les lois avaient leur couleur locale.

Sans trop nous étaler sur un sujet par ailleurs très complexe, il convient de souligner quelques points majeurs. Aux Etats-Unis, les cartels ou ententes (les pratiques horizontales) sont interdites sans possibilité de recours. On dit qu'elles sont prohibées "per se". Par contre, les pratiques verticales à l'exception des prix imposés, peuvent trouver justification, le cas échéant: c'est la "règle de raison" qui s'applique. A noter aussi que les Etats-Unis appliquent le droit pénal pour les infractions à l'interdiction des PCR horizontales.

Dans les autres pays, les PCR horizontales sont interdites en principe. C'està-dire que la loi admet des dérogations à l'interdiction, après avoir pesé le pour et le contre des pratiques en question. La loi exige une notification des PCR, qui dans plusieurs pays sont alors inscrites dans un registre normalement disponible au public. Une exception de marque: les cartels à l'exportation, enregistrés dans certains pays, ne sont pas partout publics. Dans de nombreux pays l'organisme qui se charge de l'application de la loi sur la concurrence peut interdire les PCR ainsi notifiées, elle peut aussi se borner à les enregistrer, laissant le soin aux parties éventuellement lésées d'intenter une action juridique, ou de déposer plainte auprès de l'organe de contrôle qui pourra alors se saisir du dossier, ouvrir une enquête et, le cas échéant, sévir.

Au départ, les lois européennes étaient relativement laxistes, en ce sens que l'organisme de contrôle n'avait que des pouvoirs limités, se bornant le plus souvent à faire des recommandations, l'état (habituellement le ministère de l'économie) ou les tribunaux étant seuls habilités à interdire certaines pratiques. Et encore, aux termes des lois les plus laxistes, l'organisme de contrôle devait peser les avantages et les inconvénients des PCR en question par rapport à l'intérêt public, une notion très vague de l'intérêt bien compris de la nation. Tel était dans les grandes lignes 
notre droit de la concurrence avant l'adoption de la Loi fédérale sur les cartels et organisations analogues du 20 décembre 1985.

\section{La Loi fédérale sur les cartels et le droit de la concurrence de la Communauté européenne}

La Loi du 20 décembre 1985 (entrée en vigueur le 1er juillet 1986) comporte une partie de droit civil en son chapitre 2, qui donne aux parties lésées par des atteintes à la concurrence les moyens de faire appel aux tribunaux pour défendre leurs droits, et une partie de droit administratif en son chapitre 3 , dont la responsabilité d'application incombe à la commission des cartels. La commission des cartels peut adresser au Conseil fédéral des recommandations sur la politique de la concurrence, et en particulier elle est appelée à donner préavis sur tout projet de loi, d'arrêté ou d'ordonnance fédéraux susceptibles de restreindre la concurrence. Par ailleurs, elle établit, à la demande des tribunaux et d'autorités administratives, des avis sur des questions de concurrence. Mais sa fonction principale est quand même celle de gardien de la concurrence sur le territoire de la Confédération, en ouvrant des enquêtes. La commission peut ouvrir une enquête à sa propre initiative, à la demande du Département fédéral d'économie publique (DFEP), ou après enquête préalable, lorsqu'une limitation présumée de la concurrence lui est signalée par un tiers.

Au cours de l'enquête, la commission examine si un cartel ou une organisation analogue aux termes de la Loi a des conséquences nuisibles d'ordre économique ou social. Pour cela, elle met en balance les effets utiles et les effets nuisibles du cartel. A la requête de la commission, les cartels ainsi que les tiers concernés sont tenus de fournir tous renseignements et de produire toutes pièces propres à permettre à la commission de mener à bien son enquête. Si l'obligation de renseigner est contestée, la commission a le pouvoir de statuer par décision.

Lorsqu'en conclusion de son enquête, la commission constate qu'un cartel ou une organisation analogue a des conséquences nuisibles d'ordre économique ou social, elle recommande aux intéressés de modifier ou d'annuler certaines clauses cartellaires ou certaines conventions tombant sous le coup de la loi, ou de renoncer à certains comportements de marché. Elle fixe alors un délai aux intéressés pour qu'ils déclarent par écrit s'ils acceptent la recommandation.

Lorsque les intéressés n'acceptent pas les recommandations, le DFEP peut rendre, dans les trois mois à compter de la réception du refus, une décision ordonnant les mesures nécessaires. Les intéressés ont un droit de recours auprès du Tribunal fédéral. L'inobservation de recommandations et de décisions administratives peut être punie d'une amende jusqu'à 100'000.- francs, et le refus de renseigner ou de produire des pièces suite à une mise en demeure de la commission, de même qu'un manquement aux règles de confidentialité sont passibles d'une amende jusqu'à 20'000.- francs.

Depuis l'entrée en vigueur de la nouvelle Loifédérale, la commission des cartels n'a pas chômé. Forte des pouvoirs accrus qui lui ont été conférés, elle s'est 
engagée dans un bras de fer important avec les banques, notamment, pour faire cesser les "gentlemen's agreements" qui entravaient trop nettement la concurrence dans ce secteur. Bien que les banques aient accepté certaines de ses recommandations, elle a dû recourir au DFEP pour en faire appliquer d'autres, au grand dam de l'industrie bancaire. Peu à peu, cependant, grâce à l'action de la commission, et peut-être aussi en raison des développements à l'étranger concernant la libéralisation des marchés, la déréglementation fait son chemin en Suisse. Les cartels du tabac, (longtemps en guerre avec la maison Denner S.A.), de la bière, des assurances, et du ciment disparaissent, ou sont en voie de disparition. La commission lance des enquêtes tout-azimuts: banque, assurancevie et non-vie, marché du ciment, marché du sable, gravier et béton prêt à l'emploi, branche sanitaire, articles de ski, produits diététiques, marché du lait, statuts des caisses-maladie et conventions tarifaires, marché de l'automobile, marché des appareils auditifs, marché de la farine panifiable, etc. Dans le domaine des fusions, elle s'est pour le moment limitée à des enquêtes préalables, se réservant le droit d'intervenir ultérieurement en cas d'abus de position dominante. C'est le cas, par exemple, du rachat de Konsumverein Zurich (KVZ) par Coop Suisse, de la fusion Feldschlösschen/Sibra et de la prise de participation majoritaire de Swissair dans le capital de la Crossair.

\section{Le droit de la concurrence de la Communauté européenne (CE)}

Pour sa part, le droit de la concurrence de la Communauté européenne (CE), tel qu'il est inscrit aux articles 85 et 86 du Traité de Rome, instituant la CEE, interdit tous accords horizontaux et verticaux et toutes pratiques concertées entre entreprises, susceptibles d'affecter le commerce entre Etats membres et qui ont pour objet ou pour effet d'empêcher, de restreindre ou de fausser le jeu de la concurrence à l'intérieur du marché commun. II s'agit là d'une prohibition de principe, à laquelle peuvent s'appliquer un certain nombre de dérogations, sous forme d'exemptions ou d'exceptions à condition toutefois que les PCR en question aient été notifiées au préalable à la Commission. Tout d'abord, les accords dont les effets sur la concurrence sont négligeables, (dont le chiffre d'affaires combiné est inférieur à $5 \%$ du marché communautaire ou ne dépasse pas 200 millions d'écus, soit environ $\mathbf{4 0 0}$ millions de nos francs) sont exemptés "en bloc". Ensuite, certains accords de distribution exclusive, de spécialisation, de licence, de savoir-faire, de recherche et de développement et de franchise sont exemptés, à condition que ces ententes procurent des avantages objectifs suffisants pour contrebalancer les effets restrictifs sur la concurrence. Dans certains cas, des règlements spécifiques de la Commission spécifient les conditions d'exemption de certains accords de distribution exclusive ou sélective. II en est ainsi des réseaux de distribution exclusifs dans le domaine des parfums, de l'automobile, etc.

L'article 86 du Traité concerne particulièrement les restrictions verticales imposées par des entreprises en position dominante. L'abus de position dominante, surtout s'il porte atteinte à la libre circulation des biens et des services dans 
la communauté, est très sévèrement réprimé. Ces dernières années, ce sont surtout les entraves aux "importations parallèles" qui sont tombées sous le coup de la Commission de Bruxelles. Ainsi des sociétés comme BMW, Volkswagen (dans l'automobile), Pioneer (articles Hi-fi), Toshiba (ordinateurs et photocopieurs), Distillers (whisky, alcools), et bien d'autres se sont vu infliger de lourdes amendes pour avoir interdit ou tenté d'empêcher leurs distributeurs affiliés ou indépendants de fournir des importateurs parallèles, là où les différences de prix incitaient à importer du pays membre où le prix était plus bas.

Le niveau des amendes, ainsi que les moyens tant juridiques que matériels dont dispose la Commission pour faire respecter les règles de la concurrence au sein de la CE n'ont rien à voir avec ceux - fort limités - dont dispose la commission Suisse des cartels. La méthode, tout d'abord, permet à la Commission de Bruxelles d'enquêter par surprise en perquisitionnant les locaux des entreprises incriminées, à la recherche de preuves. L'effectif dont dispose la DG-IV, division générale chargée des questions de concurrence - pour contrôler un espace beaucoup plus grand, il est vrai - est beaucoup plus important.

Mais surtout, c'est le niveau des amendes qu'elle peut infliger qui est impressionnant. Pour les infractions commises "de propos délibéré ou par négligence", la Commission peut pousser la peine jusqu'à $10 \%$ du chiffre d'affaires réalisé au cours de l'exercice précédent par chacune des entreprises ayant participé à l'infraction. Toshiba s'est ainsi vu infliger une amende de 2 millions d'écus pour avoir tenté d'empêcher les importations parallèles de photocopieurs en interdisant à ses distributeurs exclusifs dans le marché commun de vendre à l'extérieur de leur territoire exclusif à des importateurs parallèles. Tetra Pak, le fabricant suédois de produits d'emballage pour boissons, qui est installé en Suisse, s'est vu infliger une amende record de quelques 140 millions de francs suisses, pour abus de position dominante!

Au niveau du contrôle des fusions, la Commission de Bruxelles est responsable du contrôle des concentrations dont le chiffre d'affaires combiné est de 5 milliards d'écus ou plus; montant gigantesque qui lui donne quand même l'occasion de faire parler d'elle. L'interdiction faite à l'Aérospatiale de reprendre le constructeur d'avions canadien De Havilland en octobre dernier, tout comme les conditions posées à Nestlé pour la prise de contrôle de Perrier, ont déjà bien défrayé la chronique.

Pour les fusions-acquisitions qui n'atteignent pas la barre des 5 milliards d'écus, c'est le droit de la concurrence national qui entre en jeu, avec la grande diversité qui le caractérise, même au niveau des pays membres de la CE. Pour ce qui est du contrôle des PCR en général, la DG-IV se charge plus particulièrement des cas ayant des effets intra-communautaires, et le droit national se charge des atteintes à la concurrence de caractère purement national. A ce propos, le "principe de subsidiarité" dont on parle beaucoup dernièrement, veut que la Commission limite autant que faire se peut le domaine de ses compétences en faveur des administrations des pays membres. II n'empêche qu'en cas de contradiction, et ceci est important pour les candidats à une possible adhésion que nous sommes, c'est le droit communautaire qui prime. Ainsi une entente ou une fusion autorisée par 
l'organisme national de la concurrence (la commission Suisse des cartels, par exemple) parcequ'elle est jugée conforme à l'intérêt national, mais interdite par la Commission de Bruxelles, devrait être abandonnée.

\section{Evolution du droit de la concurrence dans le monde et négociations multilatérales: influence sur la Suisse}

Sous l'impulsion de la déréglementation à l'échelle planétaire à laquelle nous faisions allusion plus haut, on constate actuellement bon gré, mal gré, une tendance à l'harmonisation graduelle des divers droits de la concurrence. La plupart des pays ayant adopté de telles lois après la guerre en sont à leur quatrième ou cinquième révision. La plupart interdisent "per se" les soumissions collusoires et les prix imposés (à quelques exceptions près, comme les produits pharmaceutiques ou les publications). De même, de plus en plus de pays contrôlent les services (y compris les professions libérales) en même temps que les biens, et ils sont de plus en plus nombreux à contrôler les fusions. Une autre tendance consiste à surveiller les atteintes à la concurrence des entreprises publiques (Iorsqu'elles ne sont pas privatisées), et même des monopoles naturels, dont la justification est de plus en plus remise en question. Cestendances ne manqueront pas d'influencer la politique de la concurrence en Suisse, et déjà, nombreux sont ceux qui préconisent une nouvelle révision de la Loi fédérale sur les cartels de 1985, pour la rendre plus stricte dans son application.

Actuellement tous les pays développés ont une loi sur la concurrence. De plus, les pays du centre et de l'est de l'Europe, en transition vers l'économie de marché adoptent, l'un après l'autre, des lois antitrust. C'est le cas notamment de la Hongrie, de la Pologne et de la Tchécoslovaquie, qui sont fermement engagés dans l'économie de marché.

\section{Les pratiques commerciales restrictives et les pays en développement}

Les pays en développement sont aussi nombreux à s'intéresser à la politique de la concurrence et à passer des lois pour contrôler les PCR. L'un des principaux objectifs du Groupe d'experts des PCR de la Conférence des Nations Unies sur le commerce et le développement (CNUCED) est justement d'aider les pays en voie de développement à passer de telles lois pour encourager la concurrence et se protéger des abus dans le domaine des PCR. A l'heure actuelle, environ treize pays en développement ont de telles lois: il s'agit de l'Argentine, du Brésil, du Chili, du Pérou et du Venezuela en Amérique latine, du Gabon, du Kenya et de la Tunisie en Afrique, et de la Corée du Sud, de l'Inde, du Pakistan, du Sri-Lanka et de la Thaîlande. De plus, la Colombie, la Chine, le Ghana, l'Indonésie, les Philippines le Zaire et la Zambie préparent activement des projets de loi sur la concurrence.

Au niveau multilatéral, des négociations ont été menées de longue date pour essayer de combler le vide juridique qui existe lorsque l'on est confronté aux divers intérêts nationaux. En premier lieu, il faut savoir que rares sont les législations de 
la concurrence ayant une application extraterritoriale. Les lois antitrust américaines constituent une des rares exceptions en la matière. Pour les autres droits, les PCR dont les effets ne sont pas ressentis sur le territoire national ne sont pas couverts par la loi. Il en découle des conséquences très importantes au niveau du commerce international. Les cartels à l'exportation, par exemple, dont les effets néfastes sont ressentis à l'étranger, mais pas dans le pays d'origine, sont soit ignorés par la loi-c'est le cas de la Loi fédérale sur les cartels - , soit autorisés sous réserve de notification préalable, comme c'est le cas dans de nombreux pays: Etats-Unis, Royaume-Uni, Allemagne, notamment. II en va de même pour les cartels internationaux: seule la législation antitrust des Etats-Unis interdit explicitement aux sociétés américaines de participer à de telles ententes. Les autres droits nationaux de la concurrence sont muets à ce sujet. II est intéressant de noter à ce propos que de nombreux cartels internationaux ont leur siège en Suisse, d'où ils peuvent prospérer en toute légalité, sans aucun risque d'être inquiétés.

Dans le cas des multinationales, l'obtention de preuves peut être très difficile, surtout si celles-ci sont détenues par la maison mère ou une filiale à l'étranger. A noter aussi que de nombreux pays, pour protéger leurs entreprises contre l'action extraterritoriale du Département de la justice américaine, se sont dotés de lois visant à bloquer le transfert d'informations à l'usage des tribunaux étrangers. Tout cela n'est pas fait pour faciliter les relations internationales dans le domaine de la concurrence.

C'est pourquoi la question du contrôle des PCR au niveau multilatéral est une préoccupation de longue date des organismes internationaux. Déjà la Charte de la Havane, dont est issu le GATT, en 1947, comportait tout un chapitre dédié au contrôle des PCR, qui ne fut jamais adopté. Après nombre de réunions infructueuses sur le sujet à la Commission économique et sociale (ECOSOC) des Nations Unies et au GATT dans les années 50 et 60, le thème fut repris en 1972 par la CNUCED, afin d'étudier les effets néfastes des PCR sur le commerce et le développement des pays en développement. Depuis, un code de conduite en matière de concurrence, l'“Ensemble de principes et de règles" sur les PCR a été adopté à l'unanimité par tous les pays membres des Nations Unies en 1980. Ilcomporte, en particulier, des règles de conduite à l'usage des entreprises privées et publiques qui doivent s'abstenir de passer des accords cartellaires et autres PCR constituant un abus de position dominante, des incitations à l'usage des Etats, pour qu'ils adoptent des lois sur la concurrence, et qu'ils coopèrent activement en matière d'échange d'informations et de consultations visant à renforcer le contrôle des PCR néfastes au commerce international, y compris au commerce et au développement des pays en développement.

Cet "Ensemble", qui fut adopté sous forme de recommandation dans une résolution de l'Assemblée générale des Nations Unies, n'a pas de force contraignante, si ce n'est la force morale d'un accord adopté à l'unanimité dans une telle résolution. II n'en demeure pas moins que l'ONU continue régulièrement ses travaux en la matière au sein du Groupe d'experts des PCR qui se réunit annuellement à la CNUCED, l'objectif actuel étant d'assister les pays en déve- 
loppement et les autres (sous-entendu, également les pays en transition vers l'économie de marché), à adopter une législation nationale sur la concurrence. A plus long terme, il faudra une réforme du système du commerce international comportant des règles et disciplines sur la concurrence, tels que l'ont appelée de leurs voeux des personnalités comme $M$. Arthur Dunkel, Directeur-général du GATT et Sir Léon Brittan, Commissaire à la concurrence de la CEE.

L'Organisation pour le commerce et de développement (OCDE) à Paris, a également constitué une commission, chargée d'étudier et de rapprocher les vues des états membres (la plupart des pays développés à économie de marché y compris la Suisse) dans le domaine de la concurrence.

A part de très importantes études sur des PCR spécifiques, comme les "soumissions collusoires", "les ventes liées", ou "les obstacles au commerce international et la concurrence: leur interaction", ils ont également adopté, en 1986, une recommandation sur l'échange d'informations, une procédure de consultations et de conciliation pour aider à régler les différends qui pourraient survenir entre les pays membres de l'OCDE dans le domaine de la concurrence, et sont très actifs dans le domaine de l'assistance technique surtout pour les pays en transition.

Enfin, bien que le thème de la concurrence ne figure pas à proprement parler à l'ordre du jour des négociations de l'Uruguay Round du GATT, il est indéniable qu'une conclusion favorable de ces négociations dans le courant de 1993 aurait des répercussions importantes dans le domaine de la concurrence.

Dans le domaine de l'agriculture, la réforme de la Politique agricole commune (PAC) de la $C E$, récemment adoptée par les pays membres, où il est question d'une réduction importante des subventions à la production, de la résorption d'une partie des excédents et des subventions à l'exportation, va dans le sens des demandes américaines et du "Groupe de Cairns" pour une ouverture des marchés agricoles à la concurrence mondiale.

Dans le domaine des marchés publics, le code existant devrait être amélioré et l'ouverture à la concurrence renforcée. La Suisse, avec ou sans EEE et adhésion à la $C E$, se trouve confrontée à une pression énorme au niveau de l'Uruguay Roud.

Autre domaine d'importance capitale dans ces négociations: les services. Suivant la tendance à la déréglementation en vogue déjà au cours des années 80 , I'Uruguay Round vise à libéraliser les échanges dans un domaine où la Suisse est déjà fortement intégrée dans le marché mondial et aurait beaucoup à gagner d'une ouverture progressive des marchés voisins, mais aussi des pays du Tiers-monde. II est fort probable qu'en ce domaine, notre pays, à l'instar des autres pays développés européens, doive faire des choix difficiles, dans la mesure où l'on devrait céder du terrain dans le domaine agricole et les marchés publics, par exemple, pour gagner énormément dans l'ensemble, dans le domaine des services.

A ce propos, l'accord sur l'EEE provoyait de donner un délai d'un an à la Confédération, aux cantons et aux communes pour ouvrir à la concurrence communautaire leurs contrats de fournitures excédents 200 mille écus (environ 400 mille francs) et les contrats de travaux publics exédant les 5 millions d'écus ( 9 à 10 millions de francs suisses). Le rejet de l'EEE pourrait bien n'être qu'un répit 
de courte durée car le code sur les marchés publics, accepté par la Suisse lors du Tokyo Round devrait sortir considérablement renforcé de l'Uruguay Round. II faudra donc très probablement s'attendre à une concurrence accrue et à des temps plus rudes pour nos PME locales du domaine du bâtiment, notamment, protégées qu'elles étaient de la concurrence et donc mal préparées à se lancer à l'assaut de nouveaux marchés. Toutefois, vu les montants minimes fixés généralement dans ce type d'accords, ce sont surtout nos grandes entreprises ainsi que les PME déjà bien aguerries par la concurrence internationale qui auront tout à gagner, alors que les autres devront se préparer graduellement à affronter plus de concurrence.

Il en va de même des négociations sur les mesures d'investissement liées au commerce, les "TRIM" et celles concernant la protection intellectuelle, les "TRIP"qui se poursuivent sous l'égide de l'Uruguay Round. La Suisse est un des principaux exportateurs de capitaux et de savoir-faire (know-how) par l'intermédiaire de licences de brevets, dessins de fabrique et marques. Un assouplissement des règles relatives aux investissements directs à l'étranger et dans les pays en développement, ainsi qu'une meilleure application et une harmonisation des droits de propriété intellectuelle ne peuvent qu'être favorables à notre pays.

\section{Bilan pour la Suisse et pour les pays du Tiers Monde}

Dans l'ensemble, comme nous l'avons vu plus haut, les développements internationaux, négociations multilatérales diverses, et en particulier une conclusion favorable de l'Uruguay Round au début de 1993 devraient avoir des conséquences favorables à moyen et long terme pour la Suisse. Mais comme on ne peut, malheureusement, pas faire d'omelette sans casser des oeufs, les avantages conséquents obtenus sur le front des services, des investissements et de la propriété intellectuelle, risquent de se faire au détriment de l'agriculture et des PME de certains secteurs trop protégés jusqu'à présent, et qui devront, tôt ou tard, opérer un ajustement de structure en fonction d'une plus forte concurrence. Pour l'économie nationale, et en particulier pour le "panier de la ménagère", à terme, plus de concurrence devrait être synonyme de baisse des prix.

Pour les pays du Tiers Monde, une Suisse plus ouverte et plus compétitive devrait également comporter des avantages. Dans la mesure où les investissements et les transferts de technologie en direction des pays en développement s'intensifient, même de la part d'un petit pays comme la Suisse, la tendance devrait être favorable au progrès et au développement. Toutefois, il faut souligner que tant que des progrès déterminants n'auront pas été accomplis au niveau multilatéral pour un contrôle efficace des PCR - et avant cela, bien d'eau risque encore de couler sous les ponts-il incombera à chaque pays de se défendre soi-même contre les PCR. Et dans ce domaine, l'adoption d'un droit national de la concurrence et des moyens de l'appliquer avec efficacité est essentiel. Une révision de la loi sur les cartels donnant à la Commission des pouvoirs accrus pour démanteler les cartels à l'importation et autres entraves dans la distribution ne pourrait qu'améliorer l'accès des produits des pays du Tiers Monde au marché suisse. 


\section{Références}

1. Loi fédérale sur les cartels et organisations analogues. (Loi sur les cartels, LCart) du 20 décembre 1985.

2. Rapport annuel 1991 de la Commission des cartels: Enquêtes, Prises de position, Jugement.(1a 1992, Publication de la Commission suisse des cartels et du préposé à la surveillance des prix).

3. Vingtième rapport sur la politique de la concurrence. Commission des communautés européennes, Bruxelles 1991.

4. Bulletin des Communautés européennes, Volumes 24 (1-12)et 25 (1).

5. Guide de la législation sur les pratiques commerciales restrictives, Volumes I-IV, OCDE, Paris.

6. Politique de la concurrence dans les pays de l'OCDE, 1988-89, 1989-90; OCDE, Paris 1991 et 1992.

7. Trade Policy Review, Switzerland, Vol I \& II, GATT, Geneva, December 1991.

8. Marché intérieur communautaire. Défi et chance pour la Suisse. Publication No 109, de I'Union de Banques Suisses, Zurich, novembre 1989.

9. Où va l'agriculture? dans Le Mois économique et financier, Juin 1991, publication de la Société de Banque Suisse.

10. Banque \& Finance, Spécial Europe. No.1, Juin 1992.

11. Les soumissions collusoires, étude du secrétariat de la CNUCED, Nations Unies, New York, 1985.

12. Rapports annuels $1980,81, \ldots 1990$ de la CNUCED, sur les faits nouveaux d'ordre législatif et autre intervenus dans les pays développés et en développement en matière de contrôle des pratiques commerciales restrictives. Nations Unies, Genève.

13. Etudes économiques de l'OCDE: Suisse 1991/92, OCDE, Paris, 1992. 